\title{
Effectiveness of Orthodontic Treatment
}

\author{
AlenaKoniarová ${ }^{1}$, Eva Sedlatá Jurásková ${ }^{2}$ \\ ${ }^{I}$ M. D., OrthoSmile4U, Ltd.,Korunovo 15, 03601 Martin, Slovakia, ${ }^{2}$ M.D., PhD., Department of Orthodontics, \\ Clinicof Dental Medicine, Medical Faculty of Palacký Universityin Olomouc, Czech republic,
}

\begin{abstract}
Using PAR index / Peer Assessment Rating Index / effectiveness of orthodontic treatment was assessed in the group of patients treated with fixed and removable appliances. The group consisted of 83 patients after the end of the active phase of treatment. 34 patients were treated with removable appliances and 49 patients were treated with fixed appliances. Patients came from three orthodontic workplaces in Slovakia. In individual patients, treatment was initiated between 1st January 2010 to 31 December 2012. Measurement was carried out in dental casts made before and after the active phase of treatment using PAR meter. Results of measurement were recorded in the charts. It follows from the results of measurement that effectiveness and quality of treatment with fixed appliances was higher than in patients treated with removable appliances. In some cases of treatment with removable appliances resulting in minimal improvement, it was necessary to continue intreatment with fixed appliance.
\end{abstract}

Keywords: efficiency of orthodontic treatment, fixed orthodontic appliances, removable orthodontic appliances

\section{Introduction}

Due to an increasing number of patients per orthodontist, the issue of effectiveness of the treatment is coming forth. Effectiveness of orthodontic treatment depends on correct indication of treatment procedure, on the type of orthodontic appliance and the willingness of the patient to cooperate during orthodontic treatment. Chosen method of treatment and orthodontic appliance must take into account the duration of treatment, aesthetics and stability of outcome, patient mental maturity, economic indicators and effectiveness of treatment.

Treatment effectiveness can be measured using occlusal indices willassessthat anomaly with numerical value, reduce the subjective view of the evaluator and standardize evaluation criteria[4,5,6,7,8,15]. The indexmust follow strictrequirements.Index is to be reliable, clinically proven, sensible to the needs of a patient, acceptable for laymen as well as professionals, easy tobe processed, is to have a sufficiently sensitive scale to register severity of the anomaly, is to be suitable for statistical processing, should require minimum skills of an evaluator, should be able to respond to the needs populations [14].

To state the improvement of orthodontic anomaly, the PAR occlusal index /Peer Assessment Rating / can be used.The PAR index is used to record changes of teeth alignment after orthodontic treatment, it is possible to compare the effectiveness of various treatment methods and orthodontic appliances. In the group of patients, it is possible to give quantitative evaluation of changes in index values at the beginning and the end of treatment $[1,2,9,10,12]$.

In our work, we have usedthe PAR / Peer Assessment Rating/ index to compare the effectiveness of treatment in patients of different ages, with different malocclusionstreated with fixed and removable appliances.

\section{Material And Methods}

The sampleincluded 83 patients, 49 patients were treated with fixed and 34 patients with removable orthodontic appliances. Patients were from three orthodontic workplaces in Slovakia. Their treatment started during the period from 01.12.2010 to 31.12.2012. The measurements were carried out in dental casts, made before and after the active phase of treatment with PAR index, where the individual selected occlusal traits were scored(Fig. 1). The result which we get by summing up is the final score. The difference between the final score that is obtained by measuring the dental cast before and after treatment refers to the degree of improvement and success of treatment procedure [10]. The higher the score, the more irregular teeth. In order to balance the effect of the individual components on the overall result, components are statistically weighted, depending on different level of severity [11,13]. The Department of Orthodontics, Clinicof Dental Medicine, Medical Faculty of Palacký Universityin Olomouchas developed the formula for calculation of the weighted PAR score as a computer routine for common assessment of PAR index [16]. Numerical value is automatically transferred in the PAR nomogram [16]. Obtained numerical values were recorded in charts. PAR index includes five components:

1. The upper and lower anterior segment

2. Left and right buccal occlusion

3. Overjet 
4. Overbite

5. Centraline

There are three ways to state the improvement of orthodontic treatment with the PAR index:

A: absolute reduction in the weighted PAR score

B: Using nomogram

C: Percentage reduction in the weighted PAR score

The percentage reduction gives the most sensitive assessment. In the nomogram, the pre-treatment weighted PAR score is on the horizontal axis, the post-treatment weighted PAR score on the vertical axis.Scores of individual cases are represented on the relevant axes, then perpendiculars are drawn, their intersection indicates the degree of improvement(Fig. 2).

The degree of improvement is divided into three categories:

1. "Worse - no different"

2. "Improved"

3. "Greatly improved " $[12,13]$

In order to transfer the treated cases from the 'Worse-no different"into the category of"Improved" weighted PAR score must reduceby $30 \%$. In order to transfer the case from "Improved" into the category of "greatly improved" weighted PAR score must reduceby at least 22PAR pts. The high standard of treatment is achieved when the individual deterioration is negligible and average improvement in weighted PAR score is higher than $70 \%[11,12]$.

Dental casts were measured twice byan orthodontistusing the PAR index in the interval of two weeks. Individual scores of PAR index were summed and overall score expressed the degree of malocclusion. The difference between the total score before treatment and after the active phase of treatment reflected the degree of improvement and success of orthodontic appliance. Weighted scores were also calculated. Index has an excellent reliability and validity among different evaluators [3,11,12].

\section{Results}

The study group consisted of 83 patients after the active phase of treatment. Of these, 49 patients were treated with fixed and 34 with removable appliances. Measurement was performed on dental casts made before treatment and after the active phase of treatment, using PAR index. The average age of patients treated with removable appliance was 10,69years. The youngest was 8 years and theoldest was 14,75 years. The average age of patients treated with fixed appliance was 14,29 years. The youngest was 9,58 and the oldest was 27,33 years( Table 1).In all patients, post-treatment casts were available. In patients treated with removable appliances, the change in PAR was 12,44 points. The least change was minus 3 PAR points / worse /, the greatest improvement was 29 PAR points.

In patients treated with fixed appliances, the change in PAR score was 19,08 points. The least change was 0 PAR points / no change/ and the greatest change was 45 PAR points (Table2).

In PAR nomogram (Chart 1), there is a comparison of improvement in patients treated with fixed and removable appliances. Cases treated with fixed appliances are marked with red colour andcases treated with removable appliances are marked with blue colour. Of 34 patients treated with removable appliances, there are 5 patients in the category "Worse - no different", representing $15 \%$ of the total number. There are 25 patients in the category "Improved", representing $73 \%$ of the total number and 4 patients in the category "Greatly improved " representing $12 \%$ of the total 34 patients. Of 49 patients treated with fixed appliances, 3 patients are in the category " Worse - no different" representing 6\% of the total. In the category "Improved" there are 25 patients which is $51 \%$ and "Greatly improved" 21 patients, which is $43 \%$.

Change in PARscores inabsolute values in patients treatedwith removable appliances is given inChart 2.The bottom of Chart 2 shows PAR score in patients treated with removable appliances before treatment. It ranges from 1 to 33 PAR points. At the top of the chart, there is PAR score after treatment. It is slightly moved to the left. It follows that there was only moderateimprovement of the anomaly. It ranges between 0 to $18 \mathrm{PAR}$ points.

Chart 3 shows the change of PAR score in absolute values in patients treated with fixed appliances. The bottom of Chart 3 on a scale from 0 to 50 shows PAR score before treatment in patients treated with fixed appliances. It ranges between 6 to 47 PAR points. It follows that the cases are more complicated with regard to orthodontic treatment. The top of Chart 3 shows a significant shift to the left in the majority of cases, and therefore, a significant improvement of malocclusion. PAR scores rangesbetween 0 to 27 PAR points. 
Comparison ofpercentage changein patients treated withfixed andremovableappliances is given in Chart 4.In Graph 4, the measured results of patients treated with fixed appliances are significantly better in comparison with the results of patients treated with removable appliances. Fixed appliances are in red and removable appliances are in blue.

Out of 34 patients treated with removable appliances there is "less than $30 \%$ improvement" in 5 patients, which represents $15 \%$."Improvement of 30 to $70 \%$ " in 14 patients which is $41 \%$ and "improvement over $70 \% "$ in 15 cases, which is $44 \%$.

Three cases out of 49 patients treated with fixed appliancesbelong to the group of "less than $30 \%$ improvement", which represents 6\%. "Improvement of $30 \%-70 \% "$ was achieved in 6 cases out of 49 and "improvement over $70 \%$ " was in 40 patients, which is $82 \%$.

The degree of improvement in PAR score achieved by orthodontic treatment in patients treated with fixed and removable appliances in absolute values are given in Chart 5.

Vertical axisrepresentsthe numberof patients. Horizontal axisrepresents patients treated withfixedappliances (in red)andpatients treated withremovableappliances (in blue). "Worse-no different"are placedon the left, "Improved"in the middle and "Greatlyimproved"on the rightof the chart.In patients treated withfixedappliances, 3 cases remained without change, 25improved" and 21"significantly improved". Inpatients treated withremovableappliances, 5 remained without change, 25 improved and4 greatly improved (Table3).

Bar chart 6 represents the proportion between the category "Worse-no different," "improved" and "greatly improved" in patients treated with fixed appliances. In the group of patients treated with removable appliances, there are 5 cases whereimprovement is less than 30\%, improvement of $30 \%$ to $70 \%$ in 14 and in 15 patients improvement isover $70 \%$. In the group treated the fixed appliances, less than $30 \%$ improvementis in 3 patients, where improvement represents less than 30\%, improvement of $30 \%$ to $70 \%$ in 6 cases and improvement over $70 \%$ is in 40 patients ( Table 4). Vertical axis represents number of patients. Horizontal axis represents fixed appliances in red and removable in blue. Improvement up to $30 \%$ is indicated on the left part of the chart, improvement of $30 \%$ to $70 \%$ is indicated in the middle part of the chart, and improvement over $70 \%$ is on the right.

\section{Discussion}

The aim of our study was to compare the effectiveness of orthodontic treatment in Slovak patients treated with fixed and removable appliances. To assesssuccess of treatment, occlusal PAR index [10,12] was used to express the degree of improvement in patients before and after active phase of treatment.

The PAR index is an occlusal index used to evaluate the results of orthodontic treatment. Using the index, it is possible to convert orthodontic anomalies into numerical values and categorization format, and thus standardize evaluation criteria of malocclusion. At the same time, it helps to reduce the subjective evaluation of anomaly in mixed and permanent dentition. It has five components that are statistically weighted. The PAR index is simple, easyand convenient for statistical processing. It is sufficiently reliable even when repeatedly usedas well as among evaluators $[10,11,12]$.

The difference in score between the pre- and post-treatment cases reflects the degree of improvement of orthodontic deviation, which is a result of used treatmentmethod and chosenorthodontic appliance. It is important to realize that weighted PAR score is required to determinethe PAR index. The degree of improvement of orthodontic treatment can be recorded by:

A: absolute reduction in the weighted PAR score

B: Using nomogram

C: Use the percentage reduction in the weighted PAR score.

In the nomogram of patients treated with fixed appliances there were 3 cases evaluated "Worse -no different", representing $6 \%$ of 49 patients, 25 cases were evaluated as "Improved", representing $51 \%$ of 49 and 21 cases fell into the category of "Greatly improved", i.e. $43 \%$ of 49 patients. The percentage of the cases treated with fixed appliances is less than $30 \%$ improvement in 3 patients, that is $6 \%$ of 49 patients. Improvement from 30 to $70 \%$ in 6 cases, that is $12 \%$ of 49 patients and over $70 \%$ improvement in 40 cases, that is $82 \%$.

In the nomogram of patients treated with removable appliances, there were 5 cases as "Worse-no different", which was $15 \%$ of number 34. In 25 cases were "Improved", which was $73 \%$ of 34 patients and 4 cases were "Greatly improved ", which is $12 \%$ of 34 patients. Percentage of cases treated with removable appliances is less than $30 \%$ improvement in 5 cases, that is $15 \%$ of 34,30 to $70 \%$ improvement in 14 cases, that is $41 \%$ and over $70 \%$ improvement in 15 cases, that is $44 \%$.

Percentage improvement is more sensitive than a nomogram, because in the nomogram the cases may be divided into three categories only. In order to classify the case in the nomogram after treatment from the "Worse-no difference" into the category of "Greatly improved" there must be $70 \%$ improvement and at the same time by 22 points. A high standard of treatment is achieved when there is minimum number of cases in the 
category of "Worse-no difference", if there is an improvement in the weighted PAR score by at least $70 \%$ and if the category a "Significant improvement"includes over $40 \%$ of patients.

It follows from the results of the survey that in patients treated with fixed appliances, significant improvement reached $81,71 \%$ and the change was 19,08 PAR points. Compared with patients treated with removable appliances, improvement was $61,61 \%$ and by 12,44 PAR points.

\section{Educational Conclusions}

In casestreated withfixedappliances, anomalies improved more significantly than in cases treated with removableappliances. It is possible to achieve a higherstandard of treatment with fixed appliancesthan in casestreated withremovableappliances. Removable applianceshave limitedindications. In some cases of treatment with removable appliances resulting in minimal improvement, it was necessary to continue in treatment with fixed appliance.

The high standardof treatmentis achievedwhenwe respectthespecifics oftheindividualcase with regard to the severity ofanomaly, the patient's age, his/her abilityto cooperate, the type of facial growth, morphological pictureofanomaly, etc. Last but not least, it is up to the professionalism of dental specialist what method of treatment and orthodontic appliance he/she will choose.

\section{Acknowledgement}

I would like to thank Assoc. prof. MilosŠpidlen, M.D., PhD. forprofessional adviceand comments he is providing to me during mydoctoral $\mathrm{PhD}$. studies at the Department of Orthodontics, Clinicof Dental Medicine, Medical Faculty of Palacký Universityin Olomouc andalsothe whole teamof thisclinicforhelpandprofessional approach.

\section{References}

[1] Al Yami, E.A., Kuijpers-Jagtman, A. M.: Occlusal outcome of orthodontic treatment. Angle Orthodont. 1998, 68, No.5, p. 439-444.

[2] Buchanan, I. B., Shaw, W.C., Richmond, S., O’Brien, K.D., Andrews, M.: A comparison of the reliability and validity of the PAR index and Sumers'occlusal index. Eur. J. Orthodont. 1993, 18, p. 27-31.

[3] Buchanan, I. B., Dowing, A., Stirrups, D.R.: A comparison of the index of orthodontic treatment need applied clinically and to diagnostic records. Brit. Orthodont., 1994, 21, p. 185-188.

[4] Kamímek, M.: Quantitative Evoluation of Orthodontic Treatment Results. Part I. Clinical Standard Method. Acta Univ. Olomuc., Fac. Med., 1976, 79, p. 317-329

[5] Kamínek, M.: Quantitative Evaluation of Orthodontic Treatment Results. Part II. Therapeutical Effect Method. Acta univ. Olomuc., Fac. Med., 1976, p. 331-338.

[6] Kamínek, M.: Objektivnýregistraceortodontickýchanomálií, Čs. Stomat., 1979,79, No. 1, p. 59-67.

[7] Kamínek, M.: Treatment Results in Overjet Malocclusions. Part I. Changes of Overjet. Acta Univ. Olomuc., Fac. Med., 1979,89 p. $105-115$.

[8] Kamínek, M.: Treatment Results in Overjet Malocclusions. Part II. Changes in Occlusal Index. Acta Univ. Olomuc., 1980, 90, p. 217-227.

[9] O’Brien, K., Robbind, R., Vig, K.W.L., Shnorhokian, H., Weyant, R.J.: The effectivness of Class II, Division 1 treatment. Amer. J. Orthodont. DentofacialOrthop., 1995, 107, p. 329-334.

[10] Richmond, S., O’Brien, K. D., Buchanan, I. B., Burden, D. J.: An Introduction to Occlusal Indices, University of Manchester, Bradford, England, Ortdo-Care(UK) Ltd., 1994.

[11] Richmond, S., Shaw, W. C., O’Brien, K. D., Buchanan, I. B., Jones, R., Stephens, C. D., Roberts, C. T., Andrews, M.: The development of the PAR Index (Peer Assesment Rating): reliability and validity. Eur. J. Orthodont., 1992, 14, No.2, p. 125-139.

[12] Richmond, S., Shaw, W.C., Roberts, C.T., Andrews, M.: The PAR Index (Peer Assesment Rating): Methods to determine outcome of orthodontic treatment interms of improvement and standards. Eur. J. Orthodont., 1992, 14 No. 3, p. 180-187.

[13] Richmond, S., O’Brien, K.D., Buchanan, I.B., Burden, D.J.: An Introduction to Occlusal Indices, University of Manchester, Bradford England, Ortho-Care (UK) Ltd. 1994. /cit. Al Yami, E. A., Kuijpers- Jangtman, A.M.: Occlusal outcome of orthodontic treatment. Angle Orthodont., 1998, 68, No.5, p. 439-444/.

[14] Shaw, W.C.: Orthodontics and Occlusal Management, Oxford, London, Boston, Wright, Butterworth- Heinmann, 1993, p. 134-155, $269,286$.

[15] Shaw, W. C., Richmond, S., O’Brien , K. D.: The use of occlusal indices: A European perspective. Amer. J. Orthodont. DentofacialOrthop., 1995, 107, p. 1-10.

[16] Špidlen, M.: Efektivitaortodontickéléčby. Habil. Dis., Olomouc, 2003.

Table 1: Age categories of the sample

\begin{tabular}{|l|l|l|l|}
\hline \multicolumn{2}{|l|}{ Fixed appliances } & Removable appliances \\
\hline Mean figure & 14,29 & Mean figure & 10,69 \\
\hline Standard deviation & 2,8024 & Standard deviation & 1,346 \\
\hline Diff. max-min & 17,75 & Diff. max-min & 6,75 \\
\hline Minimum & 9,58 & Minimum & 8 \\
\hline Maximum & 27,33 & Maximum & 14,75 \\
\hline Total & 49 & Total & 34 \\
\hline
\end{tabular}


Table 2: Descriptive statistics of the PAR index. Patients treated with fixed and removable appliances.

\begin{tabular}{|l|l|l|l|}
\hline \multicolumn{2}{|l|}{ Fixed appliances } & Removable appliances \\
\hline Mean figure & 19,08 & Mean figure & 12,44 \\
\hline Standard deviation & 10,841 & Standard deviation & 7,575 \\
\hline Minimum & 0 & Minimum & -3 \\
\hline Maximum & 45 & Maximum & 29 \\
\hline Total & 49 & Total & 34 \\
\hline
\end{tabular}

Table 3: Degree of improvement in patients treated with fixed and removable appliances

\begin{tabular}{|l|l|l|l|}
\hline & No Difference/worse & Improved & Greatly improved \\
\hline Fixed appliances & 3 & 25 & 21 \\
\hline Removable appliances & 5 & 25 & 4 \\
\hline
\end{tabular}

Table 4: Degree of improvement of orthodontic treatment in \%

\begin{tabular}{|l|l|l|l|}
\hline & No Difference/worse & Improved & Greatly improved \\
\hline Fixed appliances & 3 & 6 & 40 \\
\hline Removable appliances & 5 & 14 & 15 \\
\hline
\end{tabular}

\begin{tabular}{|c|c|}
\hline $\begin{array}{l}\text { ANT-POST } \\
0 \text { None } \\
1<1 / 2 \text { unit dis } \\
2=1 / 2 \text { unit dis }\end{array}$ & \\
\hline $\begin{array}{l}\text { TRANSVERSE } \\
0 \text { None } \\
1 \text { Xbite tend }>=1 \mathrm{t} \\
21 \text { tooth in } \mathrm{xbite} \\
3>1 \text { tooth in } \mathrm{xb} \\
4>1 \text { tooth in } \mathrm{sb} \\
\end{array}$ & \\
\hline $\begin{array}{l}\text { VERTICAL } \\
0 \text { None } \\
1 \text { openb } 2 \mathrm{t}>2 \mathrm{~mm}\end{array}$ & \\
\hline $\begin{array}{l}\text { CENRELINE } \\
0<=1 / 4 \\
11 / 4-1 / 2 \\
2>1 / 2\end{array}$ & \\
\hline 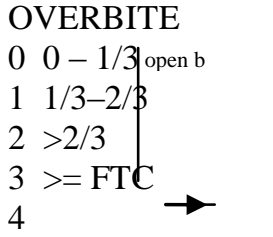 & $\begin{array}{l}- \\
-\end{array}$ \\
\hline $\begin{array}{l}\text { CONTACT Pt } \\
0- \\
1- \\
2- \\
3 \longrightarrow \\
4 \\
5 \text { impacted tooth }\end{array}$ & \\
\hline $\begin{array}{c}\text { THE } \\
\text { PAR INDEX }\end{array}$ & \\
\hline OVERJET & \\
\hline 4 & $>2 t \times b$ \\
\hline$\frac{3}{2}$ & $\begin{array}{l}2+\mathrm{vh} \\
1+\mathrm{vh}\end{array}$ \\
\hline 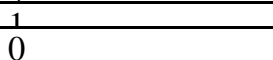 & \\
\hline
\end{tabular}

Fig.1: PAR Ruler 


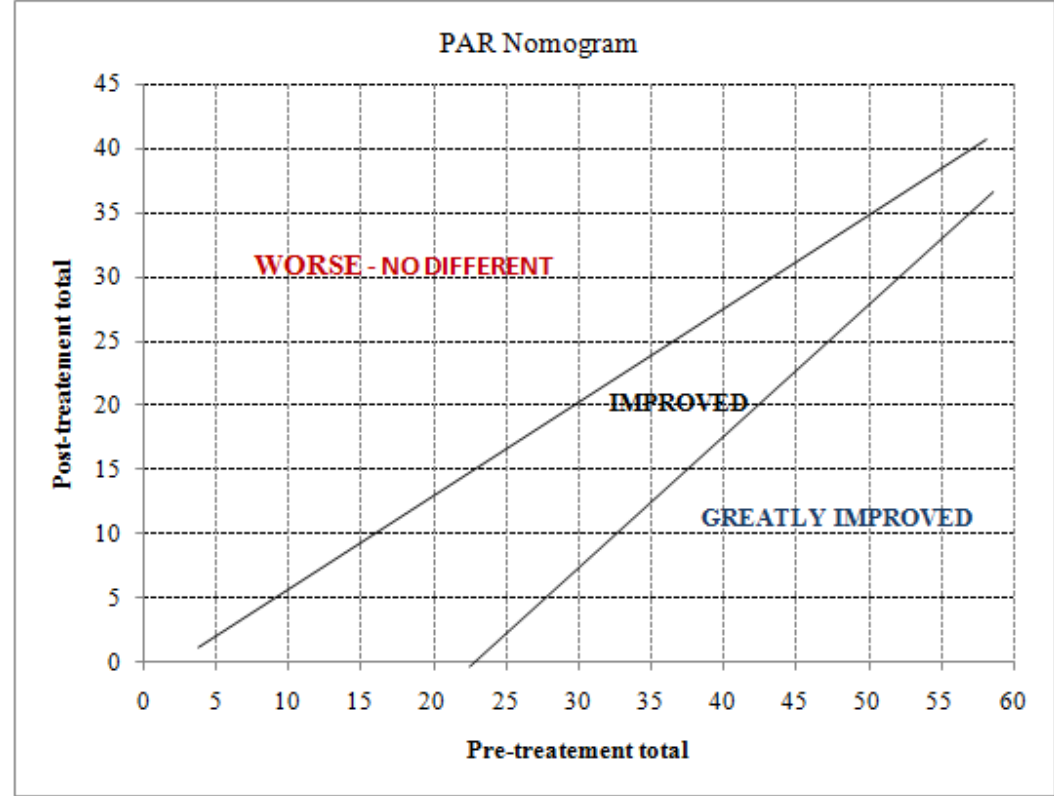

Fig.2: Nomogram
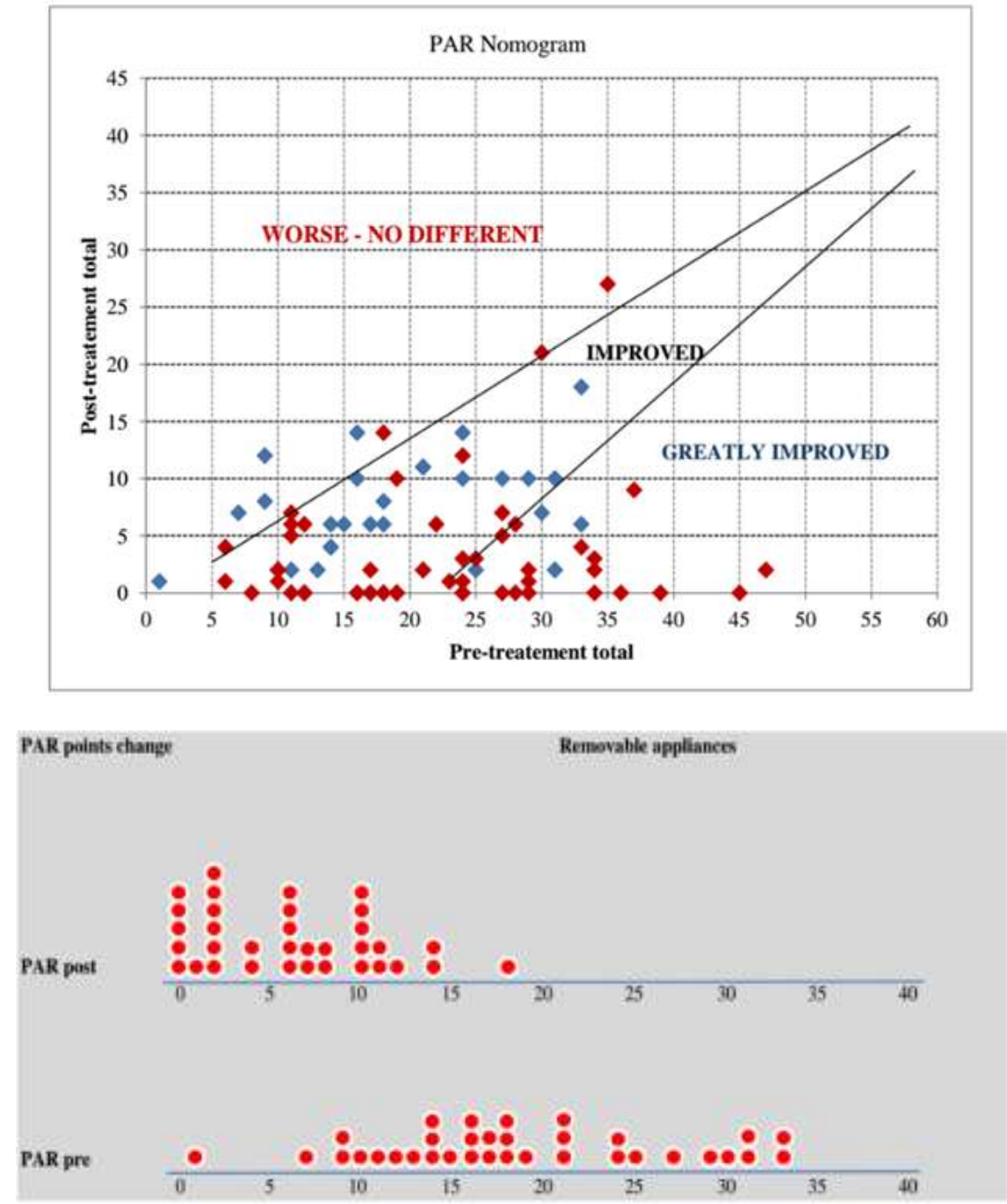

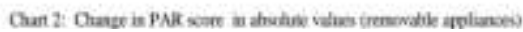




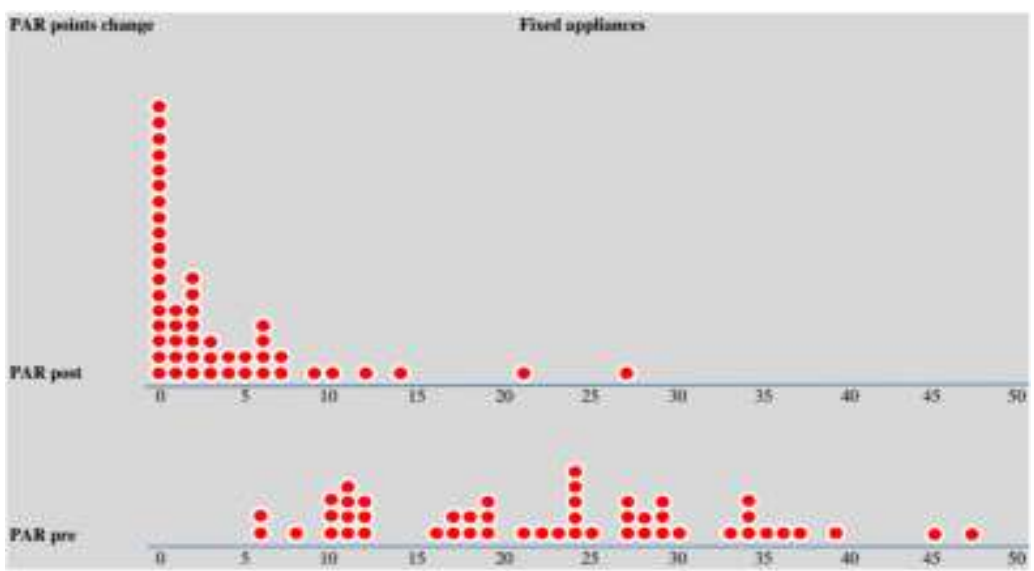

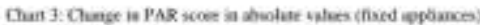

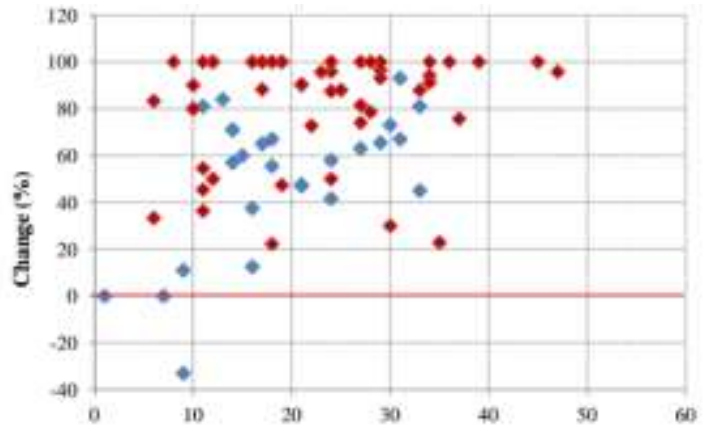

Chart 4: Comparison of treatment resalts in the group of fised appliances and in the group of remsovable applianes

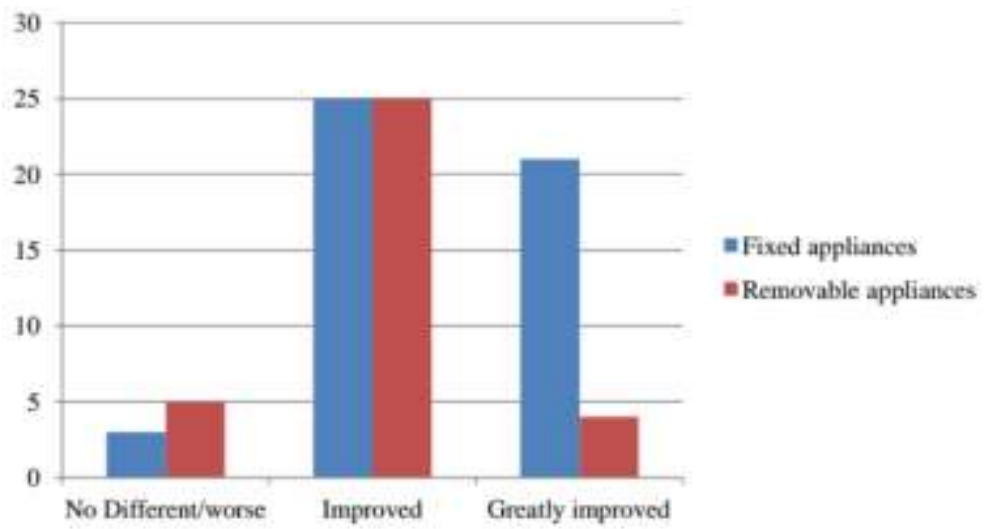

Chart 5: Degree of improvement in PAR score in absolute values

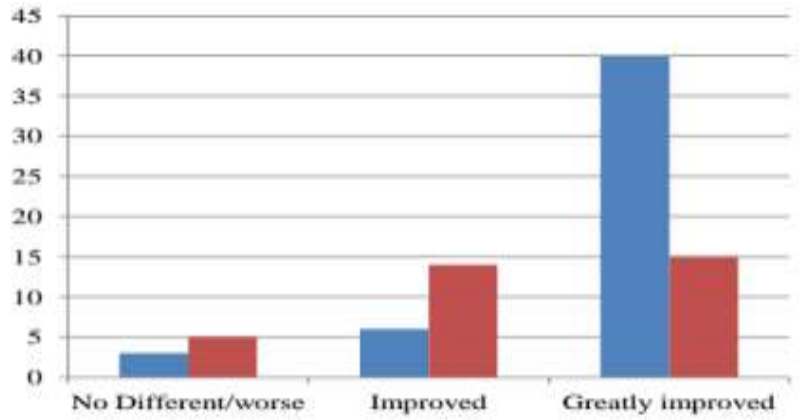

m Fixed appliances

memovable appliances

Chart 6: A bar chart, expresses a degree of improvement by orthodontic treatment in $\%$ 